\title{
A Simple Visual Analog Scale is a Valuable Tool to Assess Self-Reported Adherence in HIV-Infected Patients on Antiretroviral Treatment in a Resource-Limited Setting
} \author{
Marzolini $^{1}$, L Elzi ${ }^{1,7}$, T Klimkait ${ }^{6}$, W Langewitz ${ }^{8}$, M Battegay ${ }^{1^{\star}}$ and KIULARCO Study group \\ ${ }^{1}$ Division of Infectious Diseases and Hospital Epidemiology, University Hospital Basel, Switzerland \\ 'Ifakara Health Institute, Ifakara branch, Tanzania \\ ${ }^{3}$ Swiss Tropical and Public Health Institute of Basel, Switzerland \\ ${ }^{4}$ ISGlobal, Barcelona Ctr. Int. Health Res. (CRESIB), Hospital Clínic - Universitat de Barcelona, Barcelona, Spain \\ ${ }^{5}$ Division of Clinical Pharmacology and Toxicology, University Hospital Basel, Switzerland \\ ${ }^{6}$ Division of Molecular Virology, Department Biomedicine, Petersplatz, University of Basel, Switzerland \\ ${ }^{7}$ Ospedale Regionale di Bellinzona e Valli, Bellinzona, Switzerland \\ 8Institute of Psychosomatic Medicine, University Hospital Basel, Switzerland
}

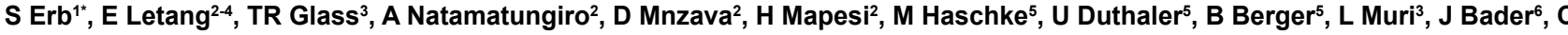

\begin{abstract}
Background: Adherence assessment in HIV-infected individuals under antiretroviral therapy (ART) is essential. The assessment tool should be reliable and easy to apply in routine clinical practice. The goal of this study was to evaluate a pictogram-enhanced visual analog scale (VAS) suitable for illiterate patients to assess self-reported adherence in ART-treated HIV-infected individuals in a resource-limited setting.
\end{abstract}

Methods: Adherence of $299 \mathrm{HIV}$-infected individuals on ART for $\geq 6$ months attending an HIV-clinic in rural Tanzania was prospectively assessed 1-3 months (visit V1) and 6-9 months (V2) after a healthcare provider training in patient-centered communication by various measures: 1) 1-10 pictogram-combined Likert VAS, 2) standardized questionnaire, 3) therapeutic drug monitoring (TDM) of ART-compounds and 4) plasma HIV-RNA.

Results: $94 \%$ of the study population had no formal or only primary education. Individuals with non-adherence were detected in $17.2 \%$ by VAS (score $\leq 9)$ and in $10.7 \%$ by questionnaire $(\geq 1$ missed ART-dose/4weeks) at $V 1$. The detection rate declined to a lesser extent with VAS $(11.7 \%, p=0.06)$ compared to the questionnaire $(5.7 \%, p=0.016)$ at V2. VAS strongly correlated with the questionnaire (kappa>0.50, $p<0.0001)$. Test agreements between TDM and VAS (kappa $\leq 0.200$ ) and between HIV-RNA and VAS (kappa $\leq 0.220$ ) were weak to fair, but slighly superior compared to the questionnaire (kappa $\leq 0.180$ and $\leq 0.060$, respectively).

Conclusion: The VAS is a valuable tool for assessing self-reported adherence in illiterate HIV-infected individuals. It is inexpensive, rapid, and easier to apply than the questionnaire. Its use should be considered in resource-limited countries where more complex measures may not be feasible.

Keywords: HIV; Visual analog scale VAS; Antiretroviral therapy ART; Self-reported adherence; Therapeutic drug monitoring TDM; Sub-Saharan Africa; Resource-limited setting

\section{Background}

Good adherence assessment is crucial for detecting HIV-infected individuals under antiretroviral treatment (ART) with suboptimal adherence, since non-adherence is associated with treatment failure [1-4]. Although no real gold standard exisits for adherence assessment, self-reported adherence assessed by standardized questionnaire is most commonly used because of its low cost and ease of use in almost all settings [5-7]. Yet, it critically depends on the healthcare providers' ability to assess adherence [8] and therefore tends to overestimate compliance [3,9-13]. Another, even simpler and faster tool to measure self-reported adherence is a visual analog scale (VAS). However, studies on the use of VAS for the assessment of adherence particularly in illiterate patients and in resource-limited setting yielded mixed results [14].

The goal of this study was to evaluate the value of an easy-to-use pictogram-enhanced visual analog scale (VAS) to assess self-reported adherence in HIV-infected individuals under ART with low literacy in a rural resource-limited setting in sub-Saharan Africa, and to compare it with a standardized and validated adherence questionnaire.

\section{Methods}

The data of this study were collected as part of an interventional cohort study published previously and conducted at the Chronic Diseases Clinic of Ifakara (CDCI), an HIV-clinic at the St. Francis Referral Hospital in rural Tanzania, from October 2013 until September 2014 [8].

All consecutive adult HIV-patients $\geq 16$ years under antiretroviral therapy (ART) for at least 6 months, presenting at the CDCI between

*Corresponding author: Dr. Stefan Erb, MD, Division of Infectious Diseases and Hospital Epidemiology, University Hospital Basel, Switzerland; Tel: +41-61-565 50 53; Fax +41-61 26531 98; E-mail: stefan.erb@usb.ch

Prof. Manuel Battegay, MD, Division of Infectious Diseases and Hospita Epidemiology, University Hospital Basel, Switzerland; Tel: +41-61-265 50 53; Fax +41-61 26531 98; E-mail: manuel.battegay@usb.ch

Received September 14, 2017; Accepted September 20, 2017; Published September 27, 2017

Citation: Erb S, Letang E, Glass TR, Natamatungiro A, Mnzava D, et al. (2017) A Simple Visual Analog Scale is a Valuable Tool to Assess Self-Reported Adherence in HIV-Infected Patients on Antiretroviral Treatment in a Resource-Limited Setting. J AIDS Clin Res 8: 731. doi: 10.4172/2155-6113.1000731

Copyright: () 2017 Erb S, et al. This is an open-access article distributed under the terms of the Creative Commons Attribution License, which permits unrestricted use, distribution, and reproduction in any medium, provided the original author and source are credited. 
Citation: Erb S, Letang E, Glass TR, Natamatungiro A, Mnzava D, et al. (2017) A Simple Visual Analog Scale is a Valuable Tool to Assess Self-Reported Adherence in HIV-Infected Patients on Antiretroviral Treatment in a Resource-Limited Setting. J AIDS Clin Res 8: 731. doi: 10.4172/21556113.1000731

Page 2 of 6

October and November 2013, were included. In December 2013, all Tanzanian healthcare providers $(\mathrm{n}=13)$ working at the CDCI with direct patient contact including all six HIV-physicians received a 2 day training in basic elements of patient-centered communication and adherence assessment. At 1-3 months (visit 1) and 6-9 months (visit 2) after the intervention, the HIV-physicians assessed adherence with the help of an adherence assessment checklist [8] using several methodologies: 1) visual analog scale (VAS), 2) standardized questionnaire, 3) therapeutic drug monitoring of ART compounds, and 4) plasma HIV-RNA. Self-reported adherence was assessed in an interview format using basic elements of patient-centered communication including a nonjudgemental manner to actively address problems with non-adherence.

The VAS was a 1-10 Likert scale enhanced with 3 pictograms (a thumb pointing downwards, horizontal, and upwards) for illiterate patients (Figure 1) and was used to assess self-reported adherence by asking: "How much of your HIV-medication have you taken in the last 4 weeks: Point with the finger on the line ranging from 0 to 10 to indicate where you think you are. 0 (thumb pointing downwards) means you have taken none of the pills, 5 (thumb is in a horizontal position) means you have taken half and 10 (or thumb is pointing upwards) means you have consistently taken every single pill".

The adherence questionnaire consisted of 2 validated questions as per standard procedure in the CDCI [4,15,16]: 1) "How often have you missed a dose of your HIV medication in the past 4 weeks: daily, more than once a week, once a week, once every second week, once a month, never?" and 2) "Did you miss ART $\geq 2$ days in a row in the last 4 weeks: yes or no?".

Self-reported non-adherence was defined as admitting to have missed $\geq 1$ dose of ART medication in the last 4 weeks by questionnaire and a VAS score $\leq 9$. We evaluated other less strict definitions of nonadherence: missed $\geq 2$ doses and drug holidays ( $\geq 2$ consecutive doses of ART medication) in the last 4 weeks determined by questionnaire and a VAS score of $\leq 8, \leq 7, \leq 6$ and $\leq 5$ points.

In addition to self-reports, adherence was assessed by measuring plasma ART drug concentrations (=therapeutic drug monitoring) of efavirenz, nevirapine, lopinavir and atazanavir and by determining HIV-RNA as described previously [8]. An inadequate subtherapeutic drug concentration as a marker for non-adherence was defined as any concentration below the $2.5^{\text {th }}$ percentile of published population based pharmacokinetic models for efavirenz $600 \mathrm{mg}$ once daily [17], nevirapine $200 \mathrm{mg}$ twice daily [18], lopinavir/ritonavir 400/100 mg twice daily [19] and atazanavir/ritonavir $300 / 100 \mathrm{mg}$ once daily [20]. Virologic failure was defined according to WHO 2014 guidelines as a detectable HIV-RNA of $\geq 1$ '000 copies/mL [21].
Kappa test were used to analyze the agreement between different adherence measurements. Test performance between the visits was analyzed by McNemar's test for categorial and paired t-test for continuous variables. A p-value below 0.05 was considered significant. All analyses were performed using STATA" software version 11 for Windows (Stata Corp, College Station, Texas, USA).

Research and ethical clearance was obtained from the Ifakara Health Institute Institutional Review Board (IHI/IRB/No.28-2013), the Medical Research Coordination Board of the Tanzanian National Institute for Medical Research (NIMR/HQIR.8a/V01.IXII762) and the Tanzanian Commission for Science and Technology (No.2014276-NA-2014-195). Written informed consent was obtained from all participants prior to enrolment in the study.

\section{Results}

Two hundred and ninty-nine HIV-patients were included in the study. Baseline characteristics have been published previously [8]. In brief, the median age was 41 years (interquartile range [IQR]: $35-48$ ) and $28.8 \%$ were male. Most patients lived $<5 \mathrm{~km}$ from the CDCI $(72.9 \%)$ and worked as farmers (85.9\%). 84.6\% had completed primary school, only $6.3 \%$ had a higher degree and $9.1 \%$ never went to school. Sixty-five percent of the patients started ART due to WHO-stage IV or CD4+ cell count $<200$ cells $/ \mu \mathrm{L}$. Median time on ART at baseline was 43 months (IQR 22-64). 67\% of the patients were on an efavirenz-based and $36.8 \%$ on a one-pill fixed-dose-combination ART regimen (efavirenz, tenofovir disoproxil fumarate, and emtricitabine or lamivudine). Nine percent were on a second-line protease inhibitor-based ART regimen with lopinavir/ritonavir. Median CD4+ cell count at study inclusion was $413 / \mu \mathrm{L}$ (IQR 268-610). Median time from the healthcare provider communication training (=intervention) to visits 1 and 2 was 63 (IQR 51-77) and 246 days (IQR 234-260), respectively. Adherence assessment by VAS was done for 261 and 240 and by questionnaire for 291 and 280 patients at visit 1 and 2, respectively.

At visit $1,17.2 \%$ of the patients reported a VAS score $\leq 9$, indicating adherence problems. At visit 2 this percentage declined to $11.7 \%$, however this was statistically not significant $(p=0.06)$. With lower VAS cut-offs the detection rate continuously declined, however, the dfferences between visit 1 and visit 2 were not statistically significant as well (Table 1).

Using a cut-off of $\leq 9$ VAS identified more individuals with adherence problems than by the questionnare which detected $10.7 \%$ of patients who reported "any adherence problem" $(\geq 1$ ART dose

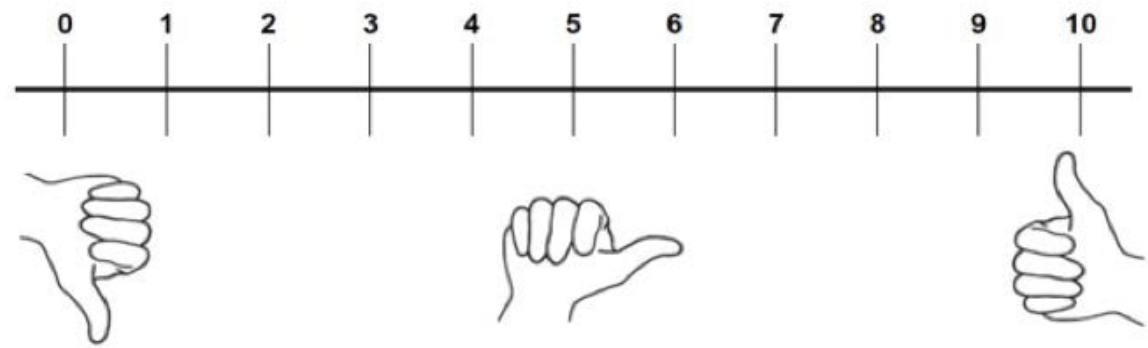

Figure 1: Pictogram-enhanced visual analog scale (VAS).

The following question was asked to the patient when showing the VAS: "How much of your HIV-medication have you taken in the last 4 weeks: Point with the finger on the line ranging from 0 to 10 to indicate where you think you are. 0 (thumb pointing downwards) means you have taken none of the pills, 5 (thumb is in a horizontal position) means you have taken half and 10 (or thumb is pointing upwards) means you have consistently taken every single pill" 
Citation: Erb S, Letang E, Glass TR, Natamatungiro A, Mnzava D, et al. (2017) A Simple Visual Analog Scale is a Valuable Tool to Assess Self-Reported Adherence in HIV-Infected Patients on Antiretroviral Treatment in a Resource-Limited Setting. J AIDS Clin Res 8: 731. doi: 10.4172/21556113.1000731

Page 3 of 6

\begin{tabular}{|c|c|c|c|c|c|}
\hline & \multicolumn{2}{|c|}{ Visit 1} & \multicolumn{2}{|c|}{ Visit 2} & p-value ${ }^{a}$ \\
\hline Adherence self-reported VAS (n, \%) & \multicolumn{2}{|c|}{$n=261$} & \multicolumn{2}{|c|}{$n=240$} & \\
\hline VAS $\leq 9$ & 45 & $17.2 \%$ & 28 & $11.7 \%$ & $p=0.06$ \\
\hline VAS $\leq 8$ & 23 & $8.8 \%$ & 13 & $5.4 \%$ & $p=0.18$ \\
\hline VAS $\leq 7$ & 7 & $2.7 \%$ & 9 & $3.7 \%$ & $p=0.56$ \\
\hline VAS $\leq 6$ & 4 & $1.5 \%$ & 5 & $2.1 \%$ & $p=0.71$ \\
\hline VAS $\leq 5$ & 3 & $1.1 \%$ & 3 & $1.3 \%$ & $p=1.00$ \\
\hline VAS median (range) & 10 & $(0-10)$ & 10 & $(0-10)$ & $p=0.12$ \\
\hline VAS mean $( \pm S D)$ & 9.65 & $(1.08)$ & 9.73 & $(1.03)$ & $p=0.42$ \\
\hline Adherence self-reported questionnaire (n, \%) & \multicolumn{2}{|c|}{$n=291$} & \multicolumn{2}{|c|}{$n=\mathbf{2 8 0}$} & \\
\hline$\geq 1$ dose missed & 31 & $10.7 \%$ & 16 & $5.7 \%$ & $p=0.02$ \\
\hline$\geq 2$ doses missed & 16 & $5.5 \%$ & 11 & $3.9 \%$ & $p=0.30$ \\
\hline$\geq 2$ consecutive doses missed & 8 & $2.7 \%$ & 9 & $3.2 \%$ & $p=0.81$ \\
\hline Therapeutic drug monitoring ${ }^{\S}(n, \%)$ & \multicolumn{2}{|c|}{$n=275$} & \multicolumn{2}{|c|}{$n=255$} & \\
\hline $\begin{array}{l}\text { Subtherapeutic drug concentrations } \\
\text { all ART compounds }\end{array}$ & 20 & $7.3 \%$ & 12 & $4.7 \%$ & $p=0.23$ \\
\hline HIV viral load $(n, \%)$ & \multicolumn{2}{|c|}{$n=286$} & \multicolumn{2}{|c|}{$n=284$} & \\
\hline HIV-RNA $\geq 1$ '000 copies/mL & 26 & $9.1 \%$ & 26 & $9.2 \%$ & $p=1.00$ \\
\hline
\end{tabular}

VAS: Visual Analog Scale; n: number of patients available for analysis; SD: Standard Deviation; ART: Antiretroviral Therapy

\$Subtherapeutic drug concentration was defined as any concentration below the $2.5^{\text {th }}$ percentile of published population based pharmacokinetic models for efavirenz [17], nevirapine [18], lopinavir/ritonavir [19] and atazanavir/ritonavir [20]

${ }^{a} p$-value refers to differences between visit 1 and visit 2 (Mc Nemar Test and paired t-test where appropriate)

Self-reported adherence assessment by VAS and questionnaire refers to a adherence period of the last 4 weeks

Table 1: Adherence assessment with VAS, questionnaire, therapeutic drug monitoring and HIV viral load.

missed in last 4 weeks) at visit 1 . Until visit 2 the detection rate by questionnaire significantly decreased to $5.7 \%(\mathrm{p}=0.02)$. When using alternative cut-offs for defining non-adherence ( $\geq 2$ missed ART doses and drug holidays in the last 4 weeks), the reported non-adherence was only $5.5 \%$ and $2.7 \%$ at visit 1 , respectively, but with a similar rates at visit 2 (Table 1$)$.

Subtherapeutic ART drug concentrations were found in $7.3 \%$ and $4.7 \%$ and virologic failure in $9.1 \%$ and $9.2 \%$ of the patients at visit 1 and 2 , respectively (Table 1 ).

Test agreement between VAS and questionnaire was strong for all different cut-offs. Test agreement between VAS and therapeutic drug monitoring showed the best performance at the first visit and with a VAS score $\leq 7$, but was in general rather weak (kappa $\leq 0.20$ ). Similar test agreement was found between questionnaire and therapeutic drug monitoring (kappa $\leq 0.18$ ). Virologic failure (HIV-RNA $\geq 1$ '000 copies $/ \mathrm{mL}$ ) significantly correlated with subtherapeutic ART drug concentration levels at visit 1 and 2 (kappa 0.25 and 0.36 , respectively, $\mathrm{p}<0.0001$ for both, not shown in the table, to a lesser extent also with VAS at visit 2 (kappa 0.216 with VAS $\leq 7, \mathrm{p}<0.001$; kappa 0.171 with VAS $\leq 8, p=0.003$ ), but not with the questionnaire (Table 2 ).

\section{Discussion}

Our in-depth study compared different methods of adherence measurements, including therapeutic drug monitoring. It shows that a simple pictogramm-enhanced 1-10 Likert-based VAS is a useful tool to assess self-reported adherence in ART treated HIV-infected patients with generally low literacy in a rural Sub-Saharan African setting. The VAS strongly correlates with a validated self-report questionnaire, but seems to be 1) more sensitive in the detection of patients with potential adherence problems, 2) easier to apply, and 3) less dependent on healthcare providers' communication and adherence assessment ability. Although test agreement between VAS and therapeutic drug monitoring (kappa $\leq 0.200$ ) as well as between VAS and viral load (kappa $\leq 0.220$ ) was rather weak, it seemed to be slightly superior than the respective correlations with a questionnaire.
Similar findings have been reported by other studies, in which VAS had exhibited a great strength of association with other self-report measures like questionnaires, but on average only minor correlation with viral load [14,22-25], irrespective if the study was done in a highor a low-income setting.

Patients' self-reported adherence or non-adherence critically depends on the communication ability of the healthcare provider to empower HIV-infected individuals to talk about their adherence problems and the applied assessment method. Adherence assessment approaches using an interview format and attempting to address the problem of adherence in a non-judgemental way usually showed a larger effect size in the detction of adherence problems [22,26,27]. In our study, the rate of self-reported non-adherence (assessed by questionnaire and VAS) varied between $5.2 \%$ and $17.1 \%$, and was higher at visit 1 compared to visit 2 . This suggests that the detection rate could be improved by training healthcare providers appropriately in adherence assessment and patient-centered communication. However, the effect of the intervention on the detection of self-reported adherence problems seemed to wean over time even though objective adherence measures of adherence like therapeutic drug monitoring and viral load did not change over time.

Notably, only few patients showed virologic failure and/or inaedequate drug concentration during the study (both $<10 \%$ ) suggesting that a good standard of medical care was provided for the study population by the healthcare providers at the CDCI.

Our study has several limitations. First, the study - like any study on the topic of adherence - suffers from the lack of a commonly accepted gold standard for the assessment of adherence. We have used therapeutic drug monitoring and viral load as objective and clinically useful surrogate markers for adherence to the ART regimen. Previous reports have described a fairly good correlation between therapeutic drug monitoring of protease inhibitors and self-reported adherence measures [28-34]. In our study, however, this correlation was rather fair to weak, both for VAS and questionnaire. This might partly be explained 
Citation: Erb S, Letang E, Glass TR, Natamatungiro A, Mnzava D, et al. (2017) A Simple Visual Analog Scale is a Valuable Tool to Assess Self-Reported Adherence in HIV-Infected Patients on Antiretroviral Treatment in a Resource-Limited Setting. J AIDS Clin Res 8: 731. doi: 10.4172/21556113.1000731

Page 4 of 6

\begin{tabular}{|c|c|c|c|c|}
\hline VAS and adherence questionnaire & Visit & Agreement & Kappa & p-value \\
\hline \multirow[t]{2}{*}{ VAS $\leq 9$ and missed $\geq 1$ ART dose } & V1 & $90.80 \%$ & 0.633 & \multirow{10}{*}{$<0.0001^{*}$} \\
\hline & V2 & $90.76 \%$ & 0.408 & \\
\hline \multirow[t]{2}{*}{ VAS $\leq 8$ and missed $\geq 1$ ART dose } & $\mathrm{V} 1$ & $92.34 \%$ & 0.588 & \\
\hline & V2 & $95.38 \%$ & 0.536 & \\
\hline \multirow[t]{2}{*}{ VAS $\leq 8$ and missed $\geq 2$ ART doses } & V1 & $95.79 \%$ & 0.696 & \\
\hline & $\mathrm{V} 2$ & $96.65 \%$ & 0.584 & \\
\hline \multirow[t]{2}{*}{ VAS $\leq 7$ and missed $\geq 1$ ART dose } & V1 & $90.04 \%$ & 0.285 & \\
\hline & $\mathrm{V} 2$ & $96.22 \%$ & 0.552 & \\
\hline \multirow[t]{2}{*}{ VAS $\leq 7$ and missed $\geq 2$ ART doses } & $\mathrm{V} 1$ & $95.79 \%$ & 0.503 & \\
\hline & V2 & $98.33 \%$ & 0.742 & \\
\hline \multicolumn{5}{|l|}{ VAS and therapeutic drug monitoring } \\
\hline \multirow[t]{3}{*}{ VAS $\leq 9$ and subtherapeutic drug concentration ${ }^{* *}$} & $\mathrm{~V} 1$ & $79.1 \%$ & 0.062 & 0.14 \\
\hline & V2 & $84.6 \%$ & -0.011 & 0.57 \\
\hline & $\mathrm{V} 1 / \mathrm{V} 2$ & $81.7 \%$ & 0.039 & 0.17 \\
\hline \multirow[t]{3}{*}{ VAS $\leq 8$ and subtherapeutic drug concentration ${ }^{* *}$} & V1 & $87.2 \%$ & 0.130 & 0.02 \\
\hline & V2 & $91.4 \%$ & 0.050 & 0.23 \\
\hline & $\mathrm{V} 1 / \mathrm{V} 2$ & $89.1 \%$ & 0.106 & 0.01 \\
\hline \multirow[t]{3}{*}{ VAS $\leq 7$ and subtherapeutic drug concentration ${ }^{\star *}$} & V1 & $92.0 \%$ & 0.198 & $<0.001$ \\
\hline & V2 & $93.2 \%$ & 0.083 & 0.10 \\
\hline & $\mathrm{V} 1 / \mathrm{V} 2$ & $92.5 \%$ & 0.152 & $<0.001$ \\
\hline \multicolumn{5}{|l|}{ VAS and HIV-RNA } \\
\hline \multirow[t]{3}{*}{ VAS $\leq 9$ and HIV-RNA >1'000 copies/mL } & $\mathrm{V} 1$ & $78.2 \%$ & 0.040 & 0.25 \\
\hline & V2 & $83.1 \%$ & 0.107 & 0.048 \\
\hline & $\mathrm{V} 1 / \mathrm{V} 2$ & $80.6 \%$ & 0.069 & 0.058 \\
\hline \multirow[t]{3}{*}{ VAS $\leq 8$ and HIV-RNA $>1$ '000 copies/mL } & V1 & $83.7 \%$ & -0.044 & 0.76 \\
\hline & V2 & $88.6 \%$ & 0.171 & 0.003 \\
\hline & $\mathrm{V} 1 / \mathrm{V} 2$ & $86.0 \%$ & 0.052 & 0.12 \\
\hline \multirow[t]{3}{*}{ VAS $\leq 7$ and HIV-RNA $>1$ '000 copies/mL } & V1 & $88.3 \%$ & -0.044 & 0.80 \\
\hline & V2 & $90.3 \%$ & 0.216 & $<0.001$ \\
\hline & $\mathrm{V} 1 / \mathrm{V} 2$ & $89.3 \%$ & 0.088 & 0.01 \\
\hline \multicolumn{5}{|l|}{ Adherence questionnaire and therapeutic drug monitoring } \\
\hline \multirow[t]{3}{*}{ Missed $\geq 1$ ART dose and subtherapeutic drug concentration ${ }^{\star *}$} & $\mathrm{~V} 1$ & $84.7 \%$ & 0.079 & 0.09 \\
\hline & V2 & $90.1 \%$ & 0.022 & 0.36 \\
\hline & $\mathrm{V} 1 / \mathrm{N} 2$ & $87.3 \%$ & 0.063 & 0.07 \\
\hline \multirow[t]{3}{*}{ Missed $\geq 2$ ART doses and subtherapeutic drug concentration ${ }^{* *}$} & V1 & $89.1 \%$ & 0.110 & 0.03 \\
\hline & V2 & $92.2 \%$ & 0.052 & 0.20 \\
\hline & $\mathrm{V} 1 / \mathrm{V} 2$ & $90.6 \%$ & 0.089 & 0.02 \\
\hline \multirow{3}{*}{$\begin{array}{l}\text { Missed } \geq 2 \text { consecutive ART doses and subtherapeutic drug } \\
\text { concentration }^{* *}\end{array}$} & V1 & $92.0 \%$ & 0.180 & $<0.001$ \\
\hline & V2 & $92.6 \%$ & 0.058 & 0.17 \\
\hline & $\mathrm{V} 1 / \mathrm{V} 2$ & $92.3 \%$ & 0.128 & $<0.001$ \\
\hline \multicolumn{5}{|l|}{ Adherence questionnaire and HIV-RNA } \\
\hline \multirow[t]{3}{*}{ Missed $\geq 1$ ART dose and HIV-RNA $\geq 1$ '000 copies/mL } & $\mathrm{V} 1$ & $82.4 \%$ & 0.010 & 0.43 \\
\hline & V2 & $86.2 \%$ & 0.025 & 0.33 \\
\hline & $\mathrm{V} 1 / \mathrm{V} 2$ & $84.3 \%$ & 0.016 & 0.35 \\
\hline \multirow[t]{3}{*}{ Missed $\geq 2$ ART doses and HIV-RNA $\geq 1$ '000 copies/mL } & V1 & $86.0 \%$ & -0.023 & 0.66 \\
\hline & V2 & $88.3 \%$ & 0.057 & 0.15 \\
\hline & $\mathrm{V} 1 / \mathrm{V} 2$ & $87.2 \%$ & 0.014 & 0.36 \\
\hline Missed $\geq 2$ consecutive ART doses and HIV-RNA $\geq 1$ '000 copies $/ \mathrm{mL}$ & V1 & $88.1 \%$ & -0.045 & 0.82 \\
\hline & V2 & $88.3 \%$ & 0.01 & 0.42 \\
\hline & V1/V2 & $88.2 \%$ & -0.017 & 0.68 \\
\hline
\end{tabular}

VAS: Visual Analog Scale; V1: Visit 1; V2: Visit 2; V1/V2: Cumulative Analysis of Sample Pairs from Visit 1 and 2

${ }^{*}$ For all analysis $p<0.0001$

$* *<2.5^{\text {th }}$ percentile of published population based pharmacokinetic models

Self-reported adherence assessment by VAS and questionnaire refers to a adherence period of the last 4 weeks

Table 2: Test agreements between VAS, adherence questionnaire, therapeutic drug monitoring and HIV-RNA.

by the long half life time of efavirenz, the ART drug most frequently used in our study, which makes the detection of non-adherence in the days prior to blood sampling for drug concentration measurements more difficult. Second, the extensive adherence assessment, including 
Citation: Erb S, Letang E, Glass TR, Natamatungiro A, Mnzava D, et al. (2017) A Simple Visual Analog Scale is a Valuable Tool to Assess Self-Reported Adherence in HIV-Infected Patients on Antiretroviral Treatment in a Resource-Limited Setting. J AIDS Clin Res 8: 731. doi: 10.4172/21556113.1000731

Page 5 of 6

both questionnaire and in addition VAS for every patient, could have influenced patients' reporting of non-adherence. Third, understanding a Likert VAS requires some ability in abstract thinking and reasoning and some degree of literacy as well. Both might be impaired in patients with only limited formal education. To overcome this inherent drawback we combined the VAS Likert-scale with pictogramms, which had previously been used successfully for adherence assessment in illiterate patients [35].

Our study also has important strengths: it was prospective and comprehensive, evaluating various subjective and objective adherence assessement measures longitudinally at different time points. With this approach we were also able to demonstrate that self-reports of non-adherence might vary according to a healthcare provider's communication skills. The focus on patients with low literacy in a resource-limited setting may provide new insights into this vulnerable and so far rarely investigated population [14]. Finally, the sample size of our study was relatively large compared to many earlier studies on the topic $[22,25-27,36]$.

\section{Conclusion}

In conclusion, we showed that HIV-infected patients can be successfully treated with high virologic response and adherence rates in rural Tanzania. A pictogramm-combined VAS is effective for the assessment of self-reported adherence and should be considered as a sole or at least adjunct measure of adherence. With its single itemstructure and visual-graphical format, the VAS is a fast and inexpensive adherence screening tool. It appears easier to apply for healthcare providers and is therefore particulary appealing in settings where more complex measures may not be feasible, including resource- or timeconstrained environments such as busy clinical care settings in subSaharan Africa.

\section{Acknowledgement}

We thank Beatrice Vetter, laboratory technician at the Division of Clinical Pharmacology and Toxicology, University Hospital Basel, Basel, Switzerland for performing all the drug concentration measurements.

\section{Funding}

This work was supported by grants from the Swiss Tropical and Public Health Institute Basel, Basel, Switzerland; Gottfried-Bangerter Stiftung, Basel, Switzerland; Freiwillige Akademische Gesellschaft FAG, Basel, Switzerland; OPOStiftung, Zürich, Switzerland; Stiftung Forschung Infektionskrankheiten SFI, Basel, Switzerland; Gilead Sciences Europe Ltd, Abbvie, Switzerland and Böhringer Ingelheim, Basel, Switzerland.

\section{References}

1. Bangsberg DR, Perry S, Charlebois ED, Clark RA, Roberston M, et al. (2001) Non-adherence to highly active antiretroviral therapy predicts progression to AIDS. AIDS 15: 1181-1183.

2. Nachega JB, Hislop M, Dowdy DW, Chaisson RE, Regensberg L, et al. (2007) Adherence to nonnucleoside reverse transcriptase inhibitor-based HIV therapy and virologic outcomes. Ann Intern Med 146: 564-573.

3. Paterson DL, Swindells S, Mohr J, Brester M, Vergis EN, et al. (2000) Adherence to protease inhibitor therapy and outcomes in patients with HIV infection. Ann Intern Med 133: 21-30.

4. Glass TR, Sterne JA, Schneider MP, De Geest S, Nicca D, et al. (2015) Selfreported nonadherence to antiretroviral therapy as a predictor of viral failure and mortality. AIDS 29: 2195-2200.

5. Chesney MA (2006) The elusive gold standard. Future perspectives for HIV adherence assessment and intervention. J Acquir Immune Defic Syndr 43 Suppl 1: S149-155

6. Nieuwkerk PT, Oort FJ (2005) Self-reported adherence to antiretroviral therapy for HIV-1 infection and virologic treatment response: A meta-analysis. J Acquir Immune Defic Syndr 38: 445-448.
7. Glass T, Cavassini M (2014) Asking about adherence - from flipping the coin to strong evidence. Swiss Med Wkly 144: w14016.

8. Erb S, Letang E, Glass TR, Natamatungiro A, Mnzava D, et al. (2017) Health care provider communication training in rural Tanzania empowers HIV-infected patients on antiretroviral therapy to discuss adherence problems. HIV Med 18: 623-634.

9. Pearson CR, Simoni JM, Hoff P, Kurth AE, Martin DP (2007) Assessing antiretroviral adherence via electronic drug monitoring and self-report: An examination of key methodological issues. AIDS Behav 11: 161-173.

10. Nieuwkerk PT, de Boer-van der Kolk IM, Prins JM, Locadia M, Sprangers MA (2010) Self-reported adherence is more predictive of virological treatment response among patients with a lower tendency towards socially desirable responding. Antivir Ther 15: 913-916.

11. Bangsberg DR (2006) Less than $95 \%$ adherence to non-nucleoside reversetranscriptase inhibitor therapy can lead to viral suppression. Clin Infect Dis 43: 939-941.

12. Schneider J, Kaplan SH, Greenfield S, Li W, Wilson IB (2004) Better physicianpatient relationships are associated with higher reported adherence to antiretroviral therapy in patients with HIV infection. J Gen Intern Med 19: 1096 1103.

13. Williams AB, Amico KR, Bova C, Womack JA (2013) A proposal for quality standards for measuring medication adherence in research. AIDS Behav 17: 284-297.

14. Finitsis DJ, Pellowski JA, Huedo-Medina TB, Fox MC, Kalichman SC (2016) Visual analogue scale (VAS) measurement of antiretroviral adherence in people living with HIV (PLWH): A meta-analysis. J Behav Med 39: 1043-1055.

15. Glass TR, De Geest S, Weber R, Vernazza PL, Rickenbach M, et al. (2006) Correlates of self-reported nonadherence to antiretroviral therapy in HIVinfected patients: The Swiss HIV cohort study. J Acquir Immune Defic Syndr 41: 385-392.

16. Glass TR, De Geest S, Hirschel B, Battegay M, Furrer H, et al. (2008) Selfreported non-adherence to antiretroviral therapy repeatedly assessed by two questions predicts treatment failure in virologically suppressed patients. Antivir Ther 13: 77-85.

17. Csajka C, Marzolini C, Fattinger K, Décosterd LA, Fellay J, et al. (2003) Population pharmacokinetics and effects of efavirenz in patients with human immunodeficiency virus infection. Clin Pharmacol Ther 73: 20-30.

18. Guidi M, Arab-Alameddine M, Rotger M, Aouri M, Telenti A, et al. (2012) Dosage optimization of treatments using population pharmacokinetic modeling and simulation. Chimia (Aarau) 66: 291-295.

19. Lubomirov R, di lulio J, Fayet A, Colombo S, Martinez R, et al. (2010) ADME pharmacogenetics: Investigation of the pharmacokinetics of the antiretrovira agent lopinavir coformulated with ritonavir. Pharmacogenet Genomics 20: 217 230 .

20. Colombo S, Buclin T, Cavassini M, Decosterd LA, Telenti A, et al. (2006) Population pharmacokinetics of atazanavir in patients with human immunodeficiency virus infection. Antimicrob Agents Chemother 50: 3801 3808.

21. WHO (2014) Consolidated guidelines on HIV prevention, diagnosis, treatment and care for key populations. WHO Library.

22. Amico KR, Fisher WA, Cornman DH, Shuper PA, Redding CG, et al. (2006) Visual analog scale of ART adherence: Association with 3 day self-report and adherence barriers. J Acquir Immune Defic Syndr 42: 455-459.

23. Segeral O, Madec Y, Ban B, Ouk V, Hak CR, et al. (2010) Simplified assessment of antiretroviral adherence and prediction of virological efficacy in HIV-infected patients in Cambodia. AIDS Res Treat 2010: 142076

24. Gianotti N, Galli L, Bocchiola B, Cahua T, Panzini P, et al. (2013) Number of daily pills, dosing schedule, self-reported adherence and health status in 2010 : A large cross-sectional study of HIV-infected patients on antiretroviral therapy. HIV Med 14: 153-160.

25. Oyugi JH, Byakika-Tusiime J, Charlebois ED, Kityo C, Mugerwa R, et al. (2004) Multiple validated measures of adherence indicate high levels of adherence to generic HIV antiretroviral therapy in a resource-limited setting. J Acquir Immune Defic Syndr 36: 1100-1102

26. Berg KM, Wilson IB, Li X, Arnsten JH (2012) Comparison of antiretroviral adherence questions. AIDS Behav 16: 461-468. 
Citation: Erb S, Letang E, Glass TR, Natamatungiro A, Mnzava D, et al. (2017) A Simple Visual Analog Scale is a Valuable Tool to Assess Self-Reported Adherence in HIV-Infected Patients on Antiretroviral Treatment in a Resource-Limited Setting. J AIDS Clin Res 8: 731. doi: 10.4172/21556113.1000731

Page 6 of 6

27. Walsh JC, Mandalia S, Gazzard BG (2002) Responses to a 1 month self-report on adherence to antiretroviral therapy are consistent with electronic data and virological treatment outcome. AIDS 16: 269-277.

28. Fabbiani M, Di Giambenedetto S, Cingolani A, Fanti I, Colafigli M, et al. (2016) Relationship between self-reported adherence, antiretroviral drug concentration measurement and self-reported symptoms in patients treated for HIV-1 infection. Infect Dis (Lond) 48: 48-55.

29. Thompson MA, Mugavero MJ, Amico KR, Cargill VA, Chang LW, et al. (2012) Guidelines for improving entry into and retention in care and antiretroviral adherence for persons with HIV: Evidence-based recommendations from an International Association of Physicians in AIDS Care panel. Ann Intern Med 156: 817-833.

30. Murri R, Ammassari A, Gallicano K, De Luca A, Cingolani A, et al. (2000) Patient-reported non-adherence to HAART is related to protease inhibitor levels. J Acquir Immune Defic Syndr 24: 123-128.

31. Hugen PW, Langebeek N, Burger DM, Zomer B, van Leusen R, et al. (2002) Assessment of adherence to HIV protease inhibitors: comparison and combination of various methods, including MEMS (electronic monitoring), patient and nurse report and therapeutic drug monitoring. J Acquir Immune Defic Syndr 30: 324-334.

32. Liechty CA, Alexander CS, Harrigan PR, Guzman JD, Charlebois ED, et al (2004) Are untimed antiretroviral drug levels useful predictors of adherence behavior? AIDS 18: 127-129.

33. Yasuda JM, Miller C, Currier JS, Forthal DN, Kemper CA, et al. (2004) The correlation between plasma concentrations of protease inhibitors, medication adherence and virological outcome in HIV-infected patients. Antivir Ther 9: 753-761.

34. Fletcher CV, Testa MA, Brundage RC, Chesney MA, Haubrich R, et al. (2005) Four measures of antiretroviral medication adherence and virologic response in AIDS clinical trials group study 359. J Acquir Immune Defic Syndr 40: 301-306.

35. Kalichman SC, Cain D, Fuhrel A, Eaton L, Di Fonzo K, et al. (2005) Assessing medication adherence self-efficacy among low-literacy patients: Development of a pictographic visual analogue scale. Health Educ Res 20: 24-35.

36. Giordano TP, Guzman D, Clark R, Charlebois ED, Bangsberg DR (2004) Measuring adherence to antiretroviral therapy in a diverse population using a visual analogue scale. HIV Clin Trials 5: 74-79. 